\title{
Estruturas secretoras de mucilagem em Hibiscus pernambucensis Arruda (Malvaceae): distribuição, caracterização morfoanatômica e histoquímica ${ }^{1}$
}

\author{
Joecildo Francisco Rocha ${ }^{2,5}$, Rafael Ribeiro Pimentel ${ }^{3}$ e Silvia Rodrigues Machado ${ }^{4}$
}

Recebido em 27/05/2011. Aceito em 1/08/2011

\begin{abstract}
RESUMO
(Estruturas secretoras de mucilagem em Hibiscus pernambucensis Arruda (Malvaceae): distribuição, caracterização morfoanatômica e histoquímica). No presente trabalho foram estudadas as estruturas secretoras de mucilagem de Hibiscus pernambucensis aos microscópios de luz e de varredura. Conhecida como guaxima-do-mangue e algodãodo-brejo, é espécie nativa encontrada no litoral brasileiro, vegetando áreas de manguezal e restinga, tendo grande importância ecológica nestes ecossistemas. É importante produtora de fibras têxteis e celulose, fornece abundante mucilagem suscetível das mesmas aplicações medicinais de outras malváceas, além da presença de tanino. Coléteres, glândulas peroladas, tricomas secretores longo-pedunculados, canais, cavidades e idioblastos foram observados. Os coléteres ocorrem no ápice caulinar, estípulas, primórdios foliares, folhas, sépalas e pétalas jovens. As glândulas peroladas são encontradas nas superfícies adaxial e abaxial dos primórdios foliares. Os canais e as cavidades encontramse distribuídos nos eixos vegetativo aéreo e reprodutivo. Os idioblastos ocorrem nas raízes, em estágios primários e secundários de desenvolvimento e no mesofilo foliar. A secreção presente nas diferentes estruturas secretoras é constituída predominantemente por polissacarídeos ácidos e neutros, podendo ocorrer proteínas, lipídeos e substâncias fenólicas. A presença de mucilagem, tanto na superfície como no interior dos órgãos, em diferentes fases do ciclo vegetativo e reprodutivo, representa um importante mecanismo adaptativo e de sobrevivência da espécie aos ambientes de restinga e mangue.
\end{abstract}

Palavras-chave: anatomia, Hibiscus pernambucensis, histoquímica, mucilagem, restinga

\begin{abstract}
(Mucilage-secreting structures of Hibiscus pernambucensis Arruda (Malvaceae): distribution, morphoanatomical and histochemical characterization). This work studied the mucilage-secreting structures of Hibiscus pernambucensis using light and scanning electron microscopy. Known as guaxima-do-mangue, algodão-do-brejo and embira-do-mangue, this species is a native shrub that occurs in mangrove and restinga along the Brazilian coast, and is important in the production of textile fibers and cellulose, provides abundant mucilage that is used medicinally like other Malvaceae species, and has tannins. The results of this work found colleters, pearl glands, long-stalked secretory trichomes, ducts, cavities and idioblasts. The colleters occur on the shoot apices, stipules, leaf primordia, leaves, young sepals and petals. The pearl glands are present in the adaxial and abaxial surface of the leaf primordia. The ducts and the cavities occur in the vegetative and reproductive shoot apices. The idioblasts occur in the roots, both in primary and secondary stages of development, and in the leaf mesophyll. The secretion of the different secretory structures is made predominantly of acids and neutral polysaccharides, proteins, lipids and phenolic substances. The presence of external and internal mucilage-secreting structures in all plant organs, at different stages of development, represents an important adaptive mechanism to restinga and mangrove environments.
\end{abstract}

Key words: anatomy, Hibiscus pernambucensis, histochemistry, mucilage, restinga

1 Parte da tese de Doutorado do primeiro Autor

2 Universidade Federal Rural do Rio de Janeiro, Instituto de Biologia, Departamento de Botânica, Seropédica, RJ, Brasil

3 Universidade Federal do Rio de Janeiro, Museu Nacional, Horto Botânico, Programa de Pós-Graduação em Ciências Biológicas (Botânica), São Cristóvão, RJ, Brasil

4 Universidade Estadual Paulista, Instituto de Biociências, Departamento de Botânica, Botucatu, SP, Brasil

5 Autor para correspondência: joecildo@ufrrj.br 


\section{Introdução}

Uma das características de grande importância taxonômina e ecológica nos representantes de Malvaceae é a presença de mucilagem, tanto em órgãos vegetativos como reprodutivos, produzida por estruturas secretoras diversas incluindo principalmente idioblastos, canais e cavidades (Scott \& Bystrom 1970; Gregory \& Baas 1989; Sawidis 1991; 1998; Rocha et al. 2002; Pimentel et al. 2011). Essas estruturas constituem sinapomorfias para a ordem Malvales (Alverson et al. 1998; Stevens 2001; Judd et al. 2009). A primeira descrição anatômica de canais e cavidades contendo mucilagem foi feita em Althaea (Malvaceae) por Meyer no ano de 1837 (apud Gregory \& Baas 1989) e a de coléteres por Rocha et al. 2002, os quais interpretam tais estruturas como coléteres baseando-se na secreção e funcionalidade dos mesmos.

As mucilagens, uma secreção de natureza mista constituída principalmente por heteropolissacarídeos ácidos e/ou neutros, proteínas e substâncias fenólicas apresentam ampla distribuição nos vegetais, formando soluções coloidais que em contato com a água tornam-se viscosas (Priolo De Lufrano \& Caffini 1981; Gregory \& Baas 1989; Roshchina \& Roshchina 1993). Essas substâncias podem desempenhar diferentes funções nas plantas, entre elas, a proteção de estruturas ou órgãos em desenvolvimento, retenção de água, reserva de carboidratos, redução da transpiração, proteção contra radiação dispersando ou refletindo a luz incidente, proteção contra herbivoria, lubrificante do ápice das raízes, captura de insetos em plantas insetívoras, como adesivo na dispersão de sementes e na regulação da germinação de sementes (Gregory \& Baas 1989; Fahn 1979; Roshchina \& Roshchina 1993; Clifford et al. 2002; Martini et al. 2003; Pimentel et al. 2011). Considerando a importância ecofisiológica da mucilagem e a diversidade de estruturas secretoras em Hibiscus L., poucos foram os estudos realizados com os representantes deste gênero (Mollenhauer 1967; Scott \& Bystrom 1970; Bakker \& Gerritsen; Dumont 1887; 1992; Bakker \& Baas 1993; Sawidis 1991; 1998; Rocha et al. 2002). Entre os trabalhos de cunho anatômico, histoquímico e ultra-estrutural, destacam-se os de Dumont (1887), sobre os canais de mucilagem de H. splendens, onde foi descrito o processo lisígeno na formação do lume das referidas estruturas. Mollenhauer (1967) descreveu as células secretoras de mucilagem de $H$. esculentus, com ênfase nos aspectos ultra-estruturais das células secretoras do pericarpo. Idioblastos mucilaginosos nos órgãos vegetativos e reprodutivos de $H$. esculentus foram descritos por Scott \& Bystrom (1970). Células mucilaginosas nas sépalas de H. rosa-sinensis, foram descritas por Sawidis $(1991,1998)$ e uma análise histoquímica e citoquímica da mucilagem foi realizada. Bakker \& Gerritsen (1992) e Bakker \& Baas (1993) realizaram estudos sobre o desenvolvimento e a anatomia dos canais mucilaginosos do ápice caulinar e folhas de $H$. schizopetalus, e caracterizaram ultra-estruturalmente as células secretoras dos canais e idioblastos em diferentes estágios de desenvolvimento, mais recentemente, Rocha et al. (2002) descreveram a anatomia de diferentes tipos de estruturas secretoras de mucilagem nas folhas de duas espécies de Hibiscus utilizando a distribuição e o número de canais como característica taxonômica e destaca que a mucilagem contribui para a adaptação das espécies ao ambiente de restinaga.

Hibiscus pernambucensis Arruda, conhecida comumente pelos nomes guaxima-do-mangue, algodão-do-brejo e embira-do-mangue, é espécie nativa de porte arbustivo encontrada ao longo do litoral brasileiro, vegetando áreas de manguezal e restinga (Pio Corrêa 1984; Lorenzi 1992).

A importância econômica e ecológica de H. pernambucensis foi destacada por diferentes autores. De acordo com Pio Corrêa (1984) é uma importante produtora de fibras têxteis e de celulose para a fabricação de papéis, fornece abundante mucilagem suscetível das mesmas aplicações medicinais de outras malváceas, além da presença de tanino. Segundo Lorenzi (1992), produz madeira leve usada na confecção de pequenos artefatos, brinquedos e caixotaria; é espécie ornamental e indicada para plantio em áreas ciliares degradadas. Tem importante papel na regeneração do mangue, visto que fornece condições propícias para o restabelecimento das espécies típicas deste habitat (Dansereau 1948; Araújo \& Maciel 1979).

O objetivo do presente trabalho foi verificar a distribuição das estruturas secretoras de mucilagem nos eixos vegetativo e reprodutivo de $H$. pernambucensis, bem como caracterizar a anatomia e a histoquímica dessas estruturas.

\section{Material e métodos}

O material botânico foi coletado em populações naturais de Hibiscus pernambucensis ocorrentes ao longo da restinga, na praia de Sahy, Município de Mangaratiba, Estado do Rio de Janeiro. Vouchers foram incluídos no Herbário "Irina Delanova Gemtchújnicov” do Departamento de Botânica, Instituto de Biociências da Universidade Estadual Paulista - Câmpus de Botucatu (BOTU), no Herbário do Museu Nacional (R) e do Departamento de Botânica da Universidade Federal Rural do Rio de Janeiro (RBR) registrados sob o número (BOTU)- 24.162, (R)-191702, (RBR)- 4093 respectivamente.

\section{Microscopia de luz}

Amostras de diferentes regiões da raiz, caule, folhas, estípulas e flores em diferentes fases de desenvolvimento foram fixadas em FAA 50 (Johansen 1940), desidratadas em série etílica crescente, incluídas em resina metacrilato (Gerrits 1991) e seccionadas em micrótomo rotativo. As secções $(8-12 \mu \mathrm{m})$ foram coradas com azul de toluidina a $0,05 \%$ em tampão acetato, $\mathrm{pH} 4,3$ (O’Brien et al. 1964) e montadas entre lâmina e lamínula com resina sintética (Gerlach 1969). Amostras de material fresco e amostras 
estocadas em álcool etílico 70\% (Johansen 1940) foram seccionadas com o auxilio de micrótomo de Ranvier. As secções $(10-12 \mu \mathrm{m})$ foram clarificadas com hipoclorito de sódio a $20 \%$, neutralizadas em água acética a $1 \%$, lavadas em água destilada, coloradas com azul de astra-safranina (Bukatsch 1972) e montadas entre lâmina e lamínula com glicerina a 50\% (Strasburger 1924).

\section{Testes histoquímicos}

Para a verificação dos compostos químicos presentes nas diferentes estruturas secretoras, a natureza das paredes celulares e o reconhecimento de alguns metabólitos celulares, secções de material fresco, obtidas com micrótomo de Ranvier, foram tratadas com Sudan IV (Johansen 1940) para lipídeos em geral; cloreto férrico a $10 \%$ para compostos fenólicos (Johansen 1940); vermelho de rutênio a 0,02\% para substâncias pécticas (Jensen 1962); reagente de Fehling para açúcares redutores (Purvis et al. 1964); anilina azul escura (Fisher 1968) para detecção de proteínas; solução de Lugol para amido (Johansen 1940); ácido periódico / Reagente de Schiff (PAS) para polissacarídeos neutros (Amaral et al. 2001 ); ácido acético e ácido clorídrico para identificação de cristais de oxalato de cálcio (Howart \& Horner 1959); floroglucinol em ácido clorídrico (Sass 1951) para evidenciar paredes lignificadas; Reagente de Nadi (David \& Card 1964) para óleos essenciais e oleoresinas. Foi aplicado tratamento controle para os testes histoquímicos de acordo com a indicação dos respectivos autores acima citados.

\section{Microscopia eletrônica de varredura (MEV)}

Amostras de folhas, estípulas e flores em diferentes fases de desenvolvimento, foram fixadas em glutaraldeído 2,5\%, tampão fosfato $0,1 \mathrm{M} \mathrm{pH} 7,3$ pós-fixadas em tetróxido de ósmio $0,5 \%$, desidratadas em série crescente de solução alcoólica, submetidas ao ponto crítico, utilizando-se $\mathrm{CO}_{2}$ como liquído de transição, metalizadas em aparelho MED 010 da Balzers Union, com camada de 10nm de ouro e analisadas ao microscópio eletrônico de varredura SEM 515 da Philips, em 20KV.

\section{Resultados}

Em Hibiscus pernambucensis foram observadas estruturas secretoras de mucilagem diversas, incluindo diferentes categorias morfológicas de tricomas como coléteres, glândulas peroladas, tricomas longo-pedunculados, além de canais, cavidades e idioblastos. A seguir é feita a descrição detalhada de cada estrutura.

\section{Coléteres}

\section{Distribuição}

Os coléteres foram observados no ápice caulinar, em ambas as superfícies dos primórdios foliares e de folhas jovens (Fig. 1A e B); na superfície adaxial das estípulas, sépalas e pétalas jovens. Nos órgãos adultos, os coléteres são ausentes ou raros e quando encontrados, apresentam-se em processo de senescência (Fig. 1C).

\section{Anatomia e histoquímica}

Os coléteres são claviformes, constituídos por uma célula basal, um pedúnculo curto unisseriado com duas a três células, uma porção intermediária bisseriada formada por três a quatro estratos celulares e uma célula apical semi-globóide. Suas células caracterizam-se por apresentar paredes espessas e de natureza pecto-celulósica revestidas por cutícula delgada, sendo as paredes anticlinais das células do pedúnculo e da célula basal mais espessas e impregnadas por substâncias lipídicas; este espessamento ocorre também na parede periclinal interna da célula basal. Em todas as células, o núcleo é esférico e conspícuo ocupando posição central, o citoplasma é denso e vacúolos pouco desenvolvidos (Fig. 1D-H).

Os coléteres têm origem a partir de sucessivas divisões periclinais de uma célula protodérmica, que se destaca das demais por ser protuberante, volumosa, com núcleo conspícuo e citoplasma denso (fig. 1D). Inicialmente, esta célula sofre uma divisão periclinal originando uma célula basal e uma apical (fig. 1E). Divisões periclinais sucessivas da célula apical dão origem a uma estrutura multicelular e unisserida (fig. 1 F e G). Subseqüentes divisões anticlinais das células medianas dessa estrutura levam à formação da porção bisseriada do coléter (fig. 1H).

No protoplasto das células dos coléteres foram detectados polissacarídeos ácidos e neutros, gotas de lipídeos e proteínas (Tab. 1), sendo os polissacarídeos os componentes predominantes da mucilagem.

\section{Glândulas peroladas}

\section{Distribuição}

As glândulas peroladas ocorrem isoladas ou agrupadas em número de três a quatro, ou associadas aos coléteres (Fig. 2A e B). Apresentam-se distribuídas esparsamente nas superfícies adaxial e abaxial dos primórdios foliares ainda protegidos dentro das estípulas e em folhas em desenvolvimento. Nota-se ainda, que as glândulas peroladas ocorrem com maior freqüência na superfície adaxial e que estão ausentes nas folhas adultas, visto que tais estruturas sofrem senescência.

\section{Anatomia e histoquímica}

As glândulas peroladas são estruturas esféricas de tamanhos distintos; bicelulares, constituídos por uma célula basal e uma célula apical semi-globóide revestida por cutícula espessa, apresentando ambas as células paredes delgadas (Fig. 2E e F), núcleo esférico e proeminente ocupando posição central na célula, citoplasma denso e pequenos vacúolos (Fig. 2C-F). Originam-se nos primórdios foliares a partir de uma célula protodérmica protuberante, que se distingue das 

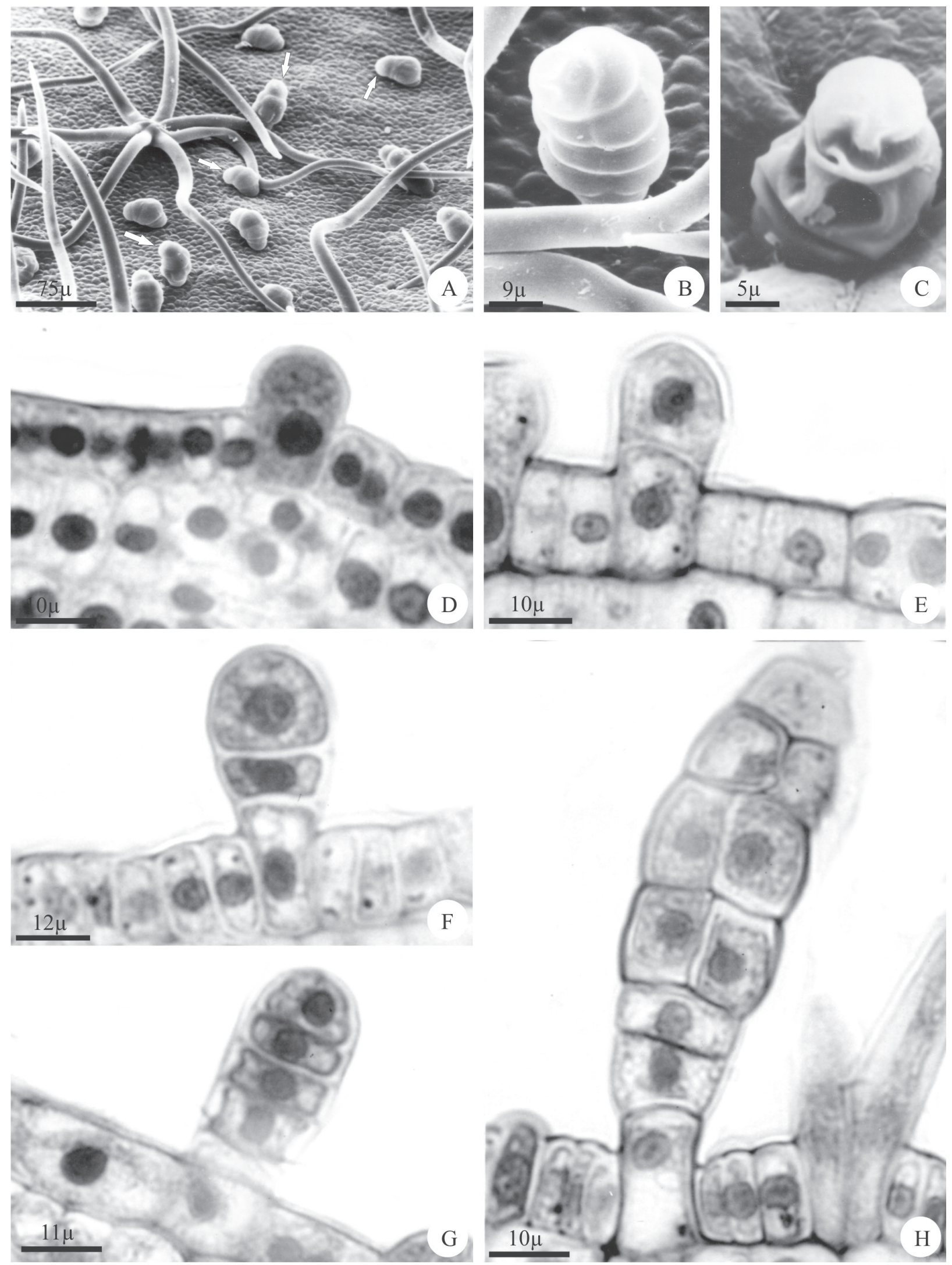

Figura 1. Coléteres. A-C. Eletromicrografia (MEV). A. Vista frontal da face adaxial da folha jovem mostrando distribuição dos coléteres (setas). B. Detalhe de um coléter. C. Coléter em processo de senescência. D-G. Secções transversais do terço médio da folha em microscopia de luz mostrando ontogênese dos coléteres. D. Célula protodérmica precursora. E. Célula precursora em divisão periclinal inicial. F. Coléter jovem com três células. G. Coléter jovem com células em divisão unicamente no plano periclinal. H. Coléter adulto mostrando estrutura multicelular. 
Tabela 1. Resultados dos testes histoquímicos para as estruturas secretoras de Hibiscus pernambucensis. (+:positivo, -:negativo).

\begin{tabular}{|c|c|c|c|c|c|c|c|}
\hline \multirow[b]{2}{*}{ Reagente } & \multirow[b]{2}{*}{ Substância } & \multirow[b]{2}{*}{ Coléteres } & \multirow[b]{2}{*}{$\begin{array}{l}\text { Glândulas } \\
\text { peroladas }\end{array}$} & \multirow[b]{2}{*}{$\begin{array}{l}\text { Tricomas } \\
\text { secretors }\end{array}$} & \multicolumn{2}{|c|}{ Canais e cavidades } & \multirow[b]{2}{*}{$\begin{array}{l}\text { Idioblastos } \\
\text { mucilaginosos }\end{array}$} \\
\hline & & & & & Lume & $\begin{array}{c}\text { Células } \\
\text { epiteliais }\end{array}$ & \\
\hline Sudan IV & Lipídeos & + & - & - & - & - & - \\
\hline Cloreto férrico & Compostos fenólicos & - & - & + & + & - & + \\
\hline Vermelho de rutênio & Substâncias pécticas & + & + & + & + & - & + \\
\hline Reagente de Fehling & Açúcares redutores & - & - & - & - & - & - \\
\hline Anilina azul escura & Proteínas & + & - & - & - & - & - \\
\hline Solução de Lugol & Amido & - & - & - & - & + & - \\
\hline Ácido periódico / reagente de Schiff & Polissacarídeos neutros & + & + & + & + & - & + \\
\hline Ácido acético e ácido clorídrico & Cristais de oxalato de cálcio & - & - & - & - & + & - \\
\hline Reagente de Nadi & Óleos essenciais e oleoresinas & - & - & - & - & - & - \\
\hline
\end{tabular}

demais células adjacentes por ser papiliforme e apresentar maior tamanho, apresentar núcleo esférico e conspícuo ocupando posição central na célula, citoplasma denso e áreas translúcidas correspondentes a pequenos vacúolos (fig. 2 C e D). Esta célula sofre uma única divisão periclinal originando uma estrutura bicelular (fig. 2E). Observa-se que tanto a célula basal quanto a apical da glândula perolada mantêm-se com as mesmas características citoplasmáticas

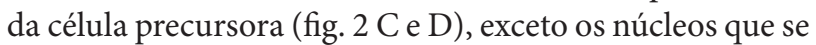
mostram menos volumosos (Fig 2E). Em fase mais avançada do desenvolvimento, ambas as células da glândula perolada diminuem de volume e o citoplasma torna-se menos denso devido ao maior desenvolvimento de pequenos e numerosos vacúolos. Observa-se ainda, o início de uma constrição lateral entre a célula basal e a apical, local onde irá ocorrer a abscisão da célula apical. Tais características indicam o início de senescência dessa estrutura (fig. 2F).

Os testes histoquímicos revelaram em ambas as células a presença de mucilagem constituída por polissacarídeos ácidos e neutros e proteínas (Tab. 1), sendo os polissacarídeos as substâncias predominantes e mais abundantes em todo protoplasto da célula apical.

\section{Tricomas secretores multicelulares longo-pedunculados}

\section{Distribuição}

Os tricomas secretores multicelulares longo-pedunculados foram registrados em flores recém-abertas e distribuem-se unicamente ao longo das ramificações do estilete, sendo tais estruturas ausentes no estigma, onde se nota a ocorrência de papilas.

\section{Anatomia e histoquímica}

Os tricomas são constituídos por uma célula basal, um pedúnculo longo unisseriado e multicelular constituido por 6-10 células, que diminuem de tamanho em direção a porção distal, e por uma cabeça secretora multicelular claviforme (Fig. 3A e B) ou romboidal (Fig. 3C e D). As células que constituem a cabeça do tricoma caracterizam-se por apresentar paredes delgadas de natureza pecto-celúlosica revestidas por cutícula delgada; núcleo de posição central ou periférica, citoplasma denso e vacúolos de tamanhos variáveis. A célula basal e as células do pedúnculo são altamente vacuoladas e possuem paredes relativamente mais espessas (Fig 3B-D).

Os testes histoquímicos revelaram que a secreção é composta por polissacarídeos ácidos e neutros e substâncias fenólicas (Tab. 1), sendo a secreção detectada unicamente nas células da cabeça dos tricomas.

\section{Canais e cavidades}

\section{Distribuição}

Os canais e cavidades ocorrem lado a lado e encontramse distribuídos nos eixos vegetativo aéreo e reprodutivo. Ocorrem no pecíolo e nervura mediana da folha (Fig 4A e F); por toda a estípula e caule, tanto no córtex (Fig. 4B) quanto na medula (Fig. 4C). No eixo reprodutivo, ocorrem no córtex e medula do pedicelo da inflorescência e por entre as células parenquimáticas de todas as peças florais (Fig. 4D e E).

\section{Anatomia e histoquímica}

Secções transversais revelaram que os canais e cavidades variam de circulares a elipsóides, apresentam lume conspícuo e epitélio secretor constituído por células de tamanho e forma variadas, com paredes pecto-celulósicas delgadas (Fig. 4B, C e G). Secções longitudinais evidenciaram a forma alongada dos canais e que os mesmos apresentam comprimentos diferentes, sendo que os maiores podem ter mais que o dobro do comprimento dos menores, enquanto que as cavidades são estruturas mais ou menos isodiamétricas (Fig. 4E e F).

Canais e cavidades adjacentes podem se fundir formando um grande espaço com formas irregulares, o qual fica totalmente preenchido pela mucilagem (Fig. $4 \mathrm{D}$ e E) dificultando, muitas vezes, a distinção dessas duas estruturas.

Os testes histoquímicos revelaram que a mucilagem presente no lume dos canais e cavidades é constituída 

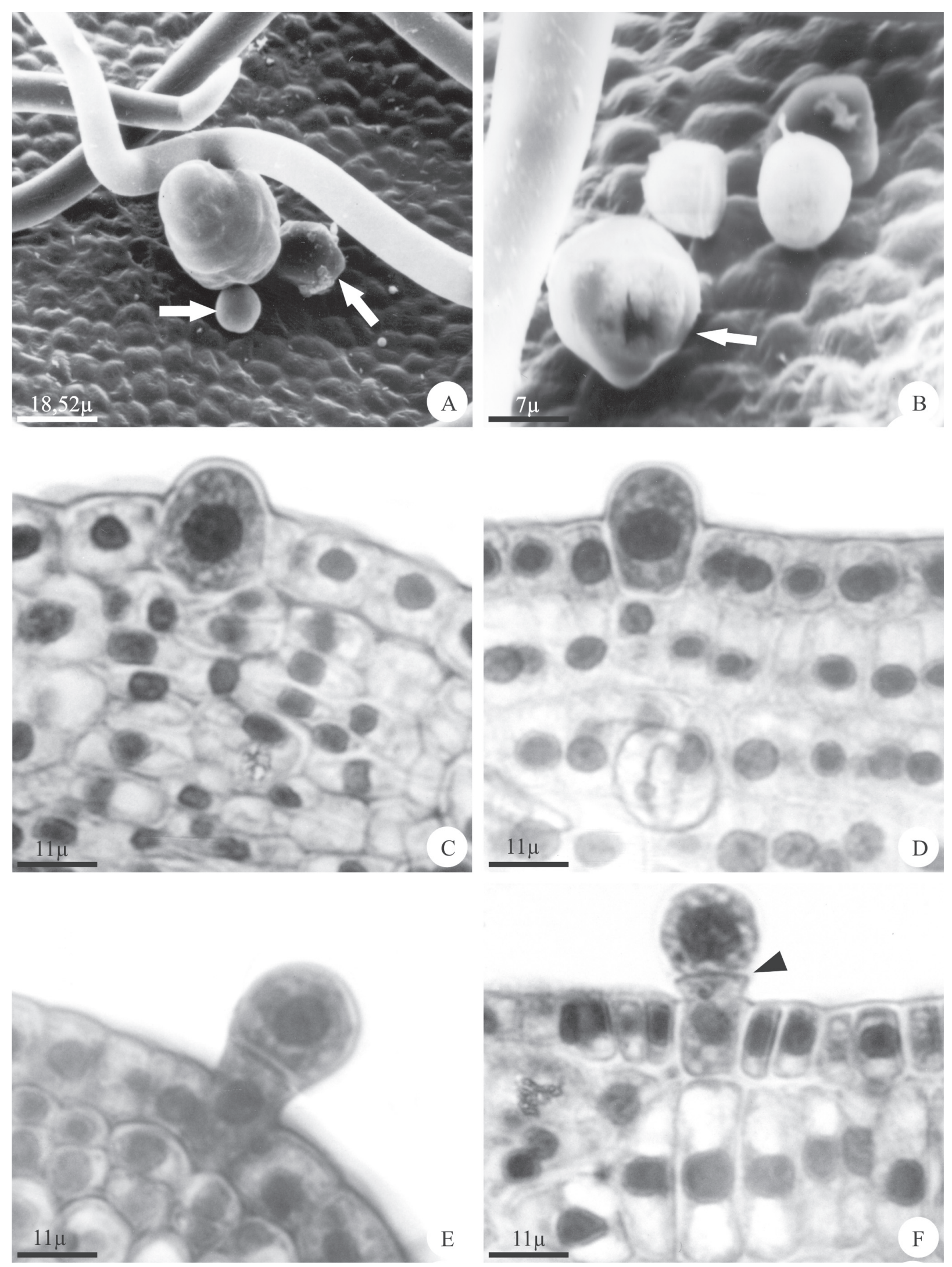

Figura 2. Glândulas peroladas. A e B. Eletromicrografias (MEV) das glândulas peroladas na superfície abaxial da folha em vista frontal. A. Glândulas peroladas (setas) associadas a um coléter. B. Detalhe da glândula perolada (seta). C-F. Secção transversal do terço médio da folha em microscopia de luz mostrando ontogênese da glândula perolada. C. Célula protodérmica precursora da glândula perolada. D. Célula protodérmica papiliforme. E. Glândula perolada mostrando célula basal e célula apical semi-globóide. F. Glândula perolada iniciando processo de senescência evidenciado pela constrição lateral entre a célula basal e a apical (cabeça de seta). 

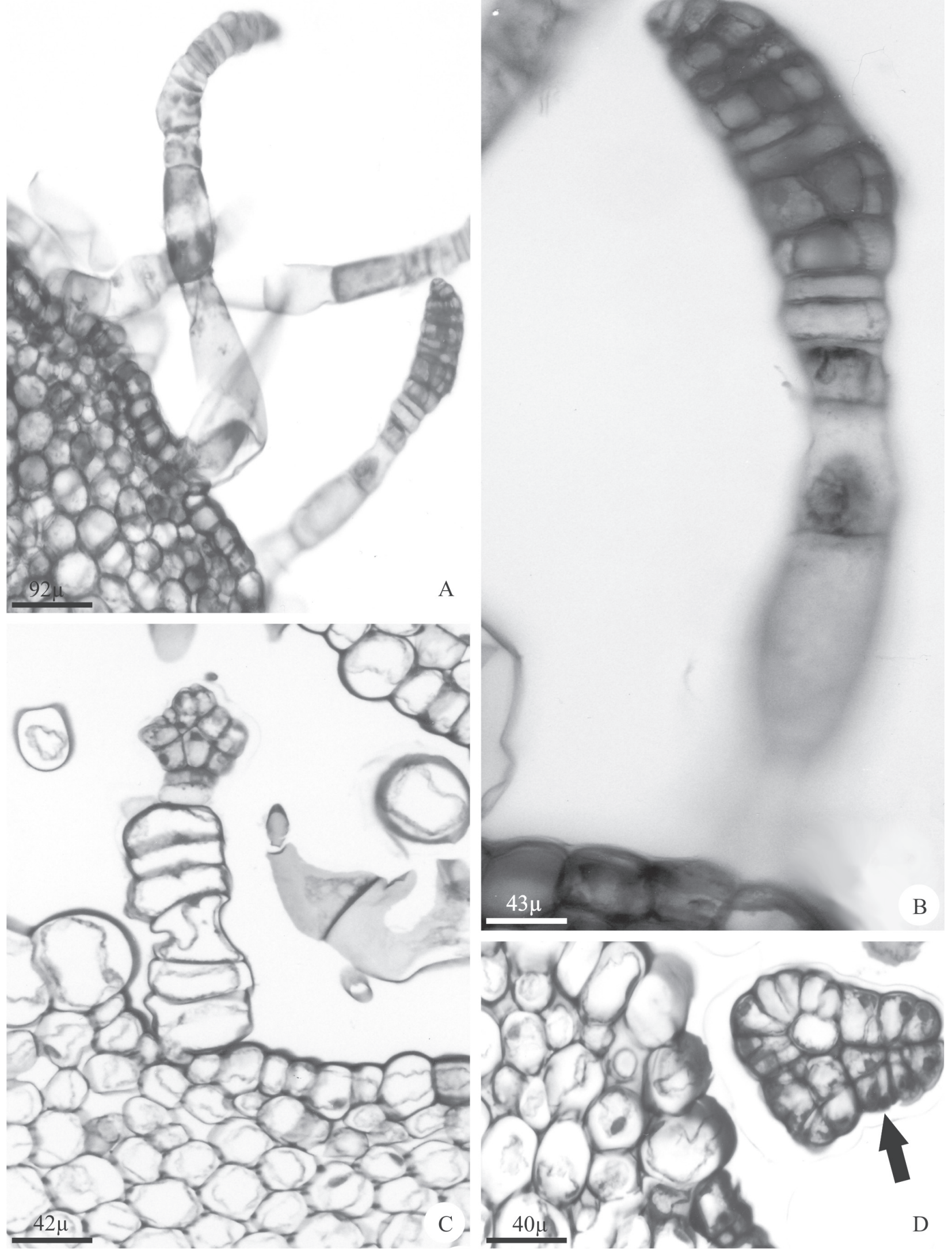

Figura 3. Tricomas secretores de mucilagem ao longo do estilete em microscopia de luz. A. Secção transversal mostrando tricomas secretores com pedúnculo longo e cabeça claviforme. B. Tricoma claviforme mostrando cabeça multicelular. C. Tricoma secretor com cabeça multicelular romboidal. D. Vista frontal da cabeça de um tricoma secretor romboidal (seta). 
predominantemente por polissacarídeos ácidos e neutros e substâncias fenólicas (Tab. 1). Grãos de amido e cristais de oxalato de cálcio do tipo drusas podem ser vistos nas células epiteliais das cavidades e canais (Tab. 1). Os polissacarídeos que constituem a mucilagem reagem com o corante Azul de Toluidina, formando lamelações concêntricas preenchendo o lume dos canais e das cavidades (Fig. 4G).

\section{Idioblastos}

\section{Distribuição}

Os idioblastos ocorrem agrupados ou isolados, sendo observados no córtex da raiz em estrutura primária, sendo mais freqüentes entre as células parenquimáticas dos estratos celulares mais internos (Fig. 5A); na casca da raiz em estrutura secundária, por entre as células do floema e da feloderme (Fig. 5B-E) e, no mesofilo da folha, por entre as células da hipoderme e do parênquima paliçádico (Fig. 5F).

Anatomia e histoquímica - Os idioblastos apresentam tamanhos variáveis, paredes pecto-celulósicas espessas e, em seç̧ão transversal, o formato varia de circular a oval. $\mathrm{O}$ conteúdo mostra-se denso, ocupa todo o protoplasto e cora-se de azul-escuro pelo Azul de Toluidina (Fig. 5A-F).

Secções longitudinais mostram que os idioblastos freqüentemente apresentam uma ou ambas as extremidades pontiagudas, sugerindo a ocorrência de crescimento apical intrusivo (Fig. 5D e F).

Os testes histoquímicos revelaram que a mucilagem presente nos idioblastos é constituída predominantemente por polissacarídeos ácidos e neutros e substâncias fenólicas (Tab.1).

\section{Discussão}

As diferentes estruturas secretoras registradas em $H$. pernambucensis são comuns para Malvaceae, sendo este o primeiro registro da ocorrência de glândulas peroladas para a referida família.

A primeira citação de coléteres na família Malvaceae foi feita por Rocha et al. (2002), nos primórdios foliares e folhas jovens de Hibiscus tiliaceus e H. pernambucensis. Nesta espécie, os coléteres são estruturas originadas exclusivamente da protoderme (Rocha et al. 2002), caracterizando-se como tricomas secretores multicelulares, conforme terminologia proposta por Solereder (1908), Fahn (1990), KronestedtRobards \& Robards (1991), para coléteres de origem protodérmica. De acordo com Thomas (1991), além da protoderme, células do meristema fundamental e do procâmbio podem estar envolvidas na formação de coléteres, sendo mais raros aqueles originados exclusivamente de células protodérmicas. Coléteres com origem mista foram descritos por Da Cunha \& Vieira (1997), Klein et al. (2004), Barreiro \& Machado (2007) para espécies de Rubiaceae e por Appezzato-da-Glória \& Estelita (2000) para espécies de Apocynaceae. Coléteres com origem exclusivamente proto- dérmica foram registrados por Paiva \& Machado (2006a) em Hymenaea stigonocarpa (Fabaceae) e por Paiva \& Martins (2011). Estes últimos autores, baseando-se em similaridades da secreção, estrutura e ultra-estrutura dos tricomas secretores calicinais de Ipomoea cairica consideram tais estruturas análogas à coléteres.

Em Hibiscus pernambucensis os coléteres têm ocorrência ampla em órgãos em desenvolvimento, sendo encontrados em estípulas, primórdios foliares, folhas, sépalas e pétalas jovens. Nos órgãos adultos os coléteres são ausentes ou raros e quando encontrados, apresentam-se degenerados ou em processo de degeneração sendo esta uma característica dessas estruturas secretoras, conforme noticiado por Uphof (1962).

O espessamento de natureza lipídica nas paredes laterais das células do pedúnculo e paredes periclinais da célula basal nos coléteres de H. pernambucensis é uma característica comum de tricomas secretores (Fahn 1990; 2000). Tal especialização parece estar relacionada com o controle do fluxo do material secretado através do apoplasto (Schnepf 1969; Shimony et al. 1973), além de promover o isolamento gradual desses tricomas, os quais posteriormente sofrem degeneração.

A análise histoquímica dos coléteres de $H$. pernambucensis revelou a presença de polissacarídeos ácidos e neutros compondo a mucilagem, lipídeos e proteínas. As referidas substâncias são comumente relatadas como fazendo parte da secreção produzida por coléteres de diferentes taxa (Kronestedt-Robards \& Robards 1991; Thomas 1991; Appezzatoda-Glória \& Estelita 2000; Rio et al. 2002; Klein et al. 2004; Paiva \& Machado 2006a,b; Barreiro \& Machado 2007), sendo geralmente a mucilagem o principal componente da secreção, conforme registrado nos coléteres de $H$. pernambucensis.

A natureza mucilaginosa da secreção produzida pelos coléteres em órgãos em desenvolvimento tem sido associada com a função de lubrificar e evitar a dessecação de gemas (Uphof 1962; Fahn 1979; 1990; Kronestedt-Robards \& Robards 1991; Thomas 1991), local onde são encontrados meristemas em início de desenvolvimento, além de proteger contra patógenos e herbívoros (Fahn 1979; Robbrecht 1988; Kronestedt-Robards \& Robards 1991; Paiva \& Machado 2006a,b; Barreiro \& Machado 2007). Klein et al. (2004) detectaram, além de carboidratos, a presença de proteínas na secreção dos coléteres de Simira glaziovii (Rubiaceae), as quais possivelmente estão associadas com mecanismo de defesa contra microorganismos. A presença de substâncias lipofílicas na mucilagem é geralmente associada com a proteção contra herbívoros e patógenos além de impermeabilização da superfície de órgãos jovens (Werker \& Fahn 1981; Ascensão et al. 1995; 1999; Corsi \& Bottega 1999). Todas as funções acima mencionadas podem ser igualmente atribuídas à secreção produzida pelos coléteres de H. pernambucensis e, embora faltem dados experimentais, a presença dessas estruturas secretoras nos órgãos em desenvolvimento possivelmente conferem proteção contra agentes bióticos e abióticos. 

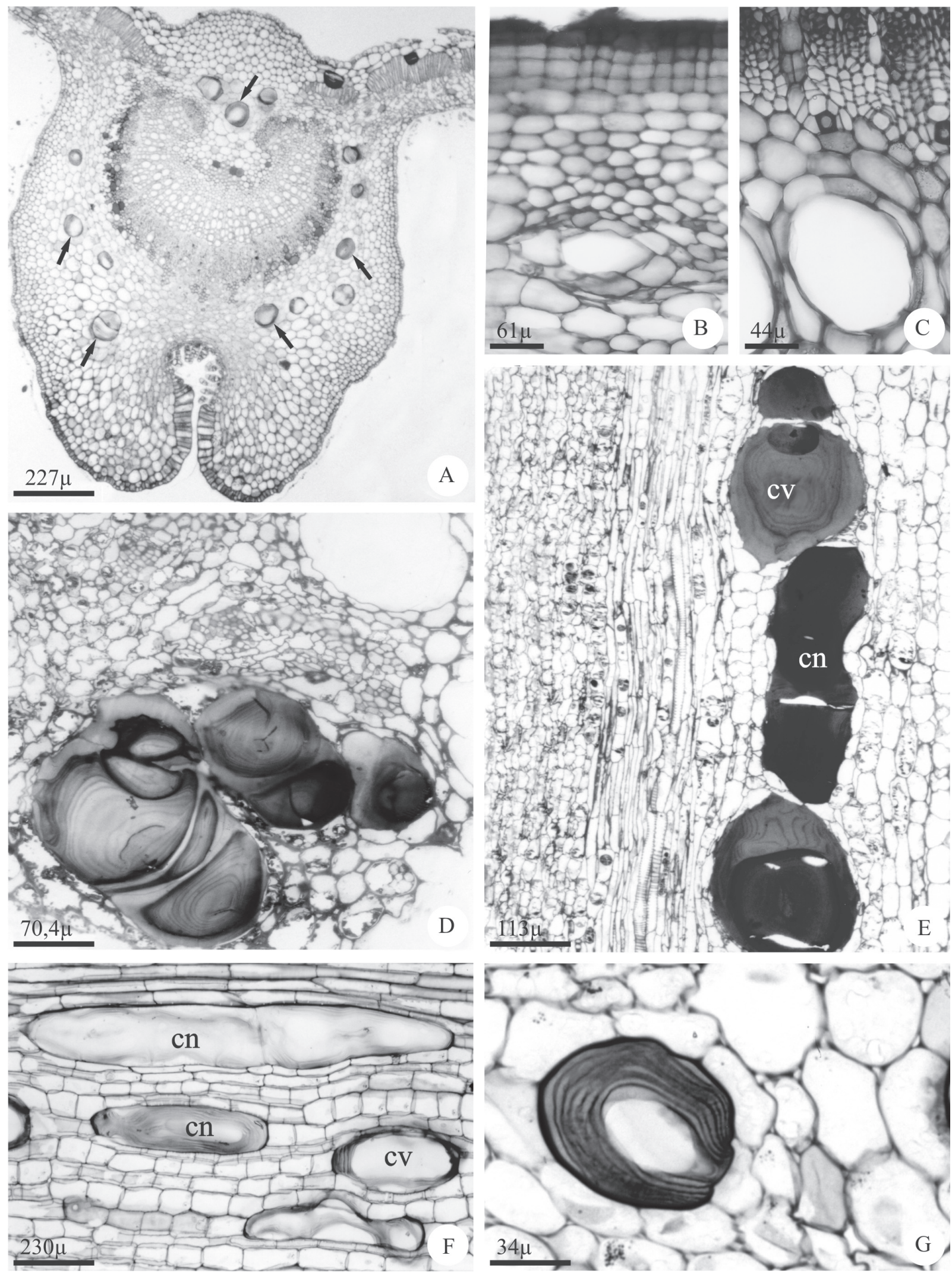

Figura 4. Canais e cavidades secretores de mucilagem em microscopia de luz. A. Secção transversal da nervura mediana da folha, mostrando distribuição dos canais e cavidades (setas). B. Canal e/ou cavidade em secção transversal no córtex do caule em estágio secundário. C. Canais e/ou cavidades em secção transversal na medula do caule em estágio primário. D. Secção transversal do terço médio da sépala mostrando canais e/ou cavidades associados entre si. E. Secção longitudinal da sépala na nervura mediana, mostrando canais $(\mathrm{Cn})$ e cavidades (Cv). F. Secção longitudinal da região mediana do pecíolo mostrando canais $(\mathrm{Cn})$ de tamanhos diferentes e cavidades (Cv). G. Detalhe mostrando células epiteliais e lume preenchido pela mucilagem corada pelo Azul de Toluidina formando lamelações. 

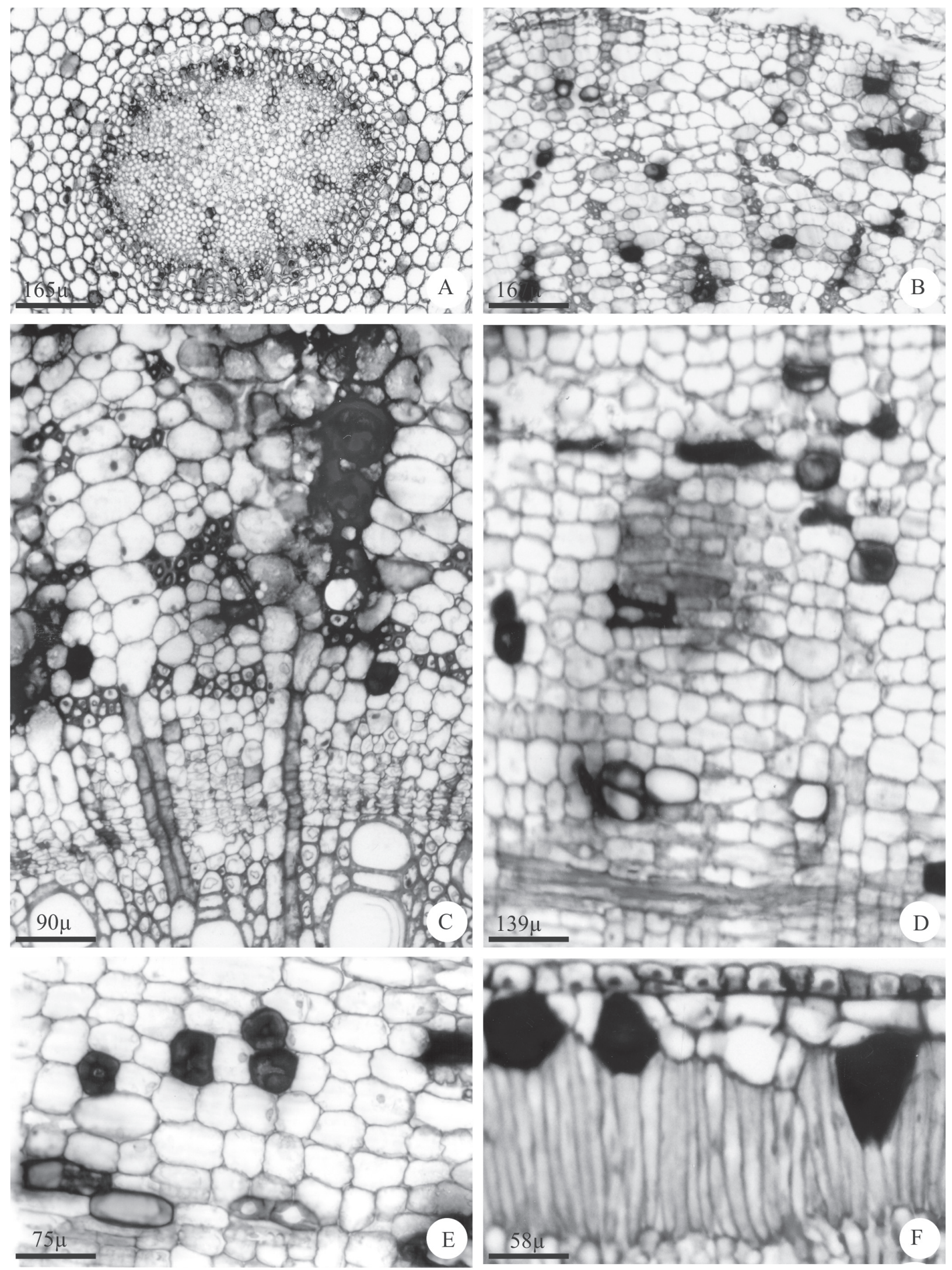

Figura 5. Idioblastos secretores em microscopia de luz. A. Secção transversal da raiz em estrutura primária mostrando idiblastos no córtex. B. Secção transversal da raiz em estrutura secundária mostrando distribuição dos idioblastos entre as células do floema e da feloderme. C. Idioblastos entre as células do floema. D. Secção longitudinal da raiz mostrando idioblastos alongados e circulares. E. Idioblastos alongados e circulares. F. Secção transversal do terço médio do mesofilo foliar mostrando idioblastos na hipoderme e entre as células do parênquima paliçádico. 
Glândulas peroladas foram relatadas para representantes da família Piperaceae, sendo a referida denominação empregada por Solereder (1908) para designar tricomas secretores que se caracterizam por apresentar uma célula apical esférica e reluzente semelhante a uma pérola.

Em H. pernambucensis tais estruturas consistem de uma célula basal e uma célula apical semi-globóide e foram observadas nas superfícies adaxial e abaxial de primórdios foliares e folhas em desenvolvimento, estando ausentes nas folhas adultas. Produzem uma secreção mucilaginosa mista, constituida de polissacarídeos ácidos e neutros e proteínas, conforme observado em espécies diferentes (Solereder 1908; Metcalfe \& Chalk 1950).

Estruturas similares foram registradas por Silva \& Machado (1999a; b) em Piper regnellii var. regnellii (Piperaceae), onde foram detectados polissacarídeos, proteínas e lipídeos. Nesta espécie, a secreção mucilaginosa é eliminada através do rompimento da cutícula, recobrindo totalmente a superfície das folhas em desenvolvimento (Silva \& Machado 1999a; b). De acordo com as referidas autoras, à medida que o limbo foliar se expande, as glândulas peroladas sofrem abscisão deixando uma cicatriz na superfície foliar ou, eventualmente, permanecem em folhas adultas. Folhas com tais estruturas são muito visitadas por formigas. Tal observação foi feita também por Rickson \& Risch (1984) para estruturas epidérmicas presentes no pecíolo de Pipercenocladum. Segundo Solereder (1908), as glândulas peroladas presentes em espécies de Piperaceae são decíduas ou podem permanecer sob determinadas condições e se correlacionam com corpos alimentares. Entretanto, em H. pernambucensis não foi observada nenhuma interação destas estruturas com formigas ou qualquer outra espécie de inseto. Desde modo, acredita-se que as referidas estruturas estão primariamente envolvidas com a lubrificação e proteção contra dessecação dos primórdios foliares e folhas em desenvolvimento.

A ocorrência de tricomas secretores longo-pedunculados com morfologia semelhante à observada no estilete de H. pernambucensis é uma característica mencionada por diferentes autores (Youngman \& Pande 1929; Ragonese 1960; Imandar \& Chohan 1969a; b) para algumas espécies de Malvaceae. Entretanto, os referidos autores não mencionam a natureza da secreção produzida por estas estruturas. Em H. pernambucensis foi detectada mucilagem constituída unicamente de polissacarídeos ácidos e neutros compondo a secreção presente nas células da cabeça secretora.

De acordo com Fahn (1979), o estigma de muitas plantas secreta substâncias contendo açúcares, lipídeos e outros compostos, as quais estão relacionadas principalmente com a função de captura dos grãos de pólen e proteção contra a dessecação. Em H. pernambucensis os tricomas foram registrados somente nos ramos do estilete de flores recém-abertas, estando ausentes no estigma, onde se notam papilas. Desta forma, a mucilagem produzida pelos referidos tricomas provavelmente tem como principal função lubrificar e proteger o estilete contra a dessecação, conforme relatado por Meyberg (1988) para os tricomas secretores de Nymphoides peltata.

A presença, o número e a distribuição dos canais são considerados como um valioso caráter taxonômico para a família (Solereder 1908; Webber 1938; Metcalfe \& Chalk 1950; Esau 1974; Rocha \& Neves 2000; Rocha et al. 2002).

A distribuição e os aspectos estruturais dos canais e cavidades secretores de mucilagem, presentes nos diferentes órgãos de H. pernambucensis, estão, de um modo geral, de acordo com as descrições para as diferentes espécies de Malvaceae (Mollenhauer 1967; Scott \& Bystrom 1970; Bakker \& Gerritsen 1992; Bakker \& Baas 1993; Sawidis 1991; 1998; Rocha et al. 2002; Pimentel et. al. 2011) e corroboram o estabelecimento de Malvales como grupo monofilético.

Em H. pernambucensis os canais e cavidades contíguos podem se fundir através da lise de células que os separam, conforme também observado por Bouchet \& Deysson (1974) nos canais de Sterculia bidwilli. De acordo com os autores, o aumento do lume das referidas estruturas se dá por histólise de células vizinhas, sendo esse mecanismo denominado "degenerescência gomosa".

De acordo com Rougier \& Chaboud (1985), a mucilagem nas raízes tem função de restringir o atrito entre o ápice radicular e o solo, proteger da dessecação e facilitar a difusão de nutrientes, sendo sua ocorrência relacionada com a superfície do órgão. Estruturas internas secretoras de mucilagem nas raízes são de um modo geral descritas apenas na região cortical de poucas espécies, podendo tal fato ser atribuído a escassez de estudos anatômicos de órgãos subterrâneos (Gregory \& Baas 1989). Nas raízes de H. pernambucensis a distribuição dos idioblastos de mucilagem difere, de um modo geral, dos relatos em literatura. Essas estruturas foram observadas em órgãos vegetativos e reprodutivos de H. esculentus por Scott \& Bystrom (1970) e, segundo os autores, estão ausentes nas regiões meristemáticas e de alongamento das raízes primárias. Entretanto, após a instalação do crescimento secundário e formação da casca, bem como na região de transição da raiz e do caule, esporadicamente foram encontrados idioblastos mucilaginosos.

A mucilagem presente nos canais, cavidades e idioblastos de H. pernambucensis é composta por polissacarídeos ácidos e neutros e substâncias fenólicas. Hegnauer (1969 apud Gregory \& Baas 1989) sugere que em Althaea officinalis as diferentes frações da mucilagem apresentam funções distintas. A reserva de água é feita pela fração ácida, a qual tem seu pico de produção nos meses do verão e a reserva de carboidratos é feita pela fração neutra, a qual mostra um máximo de produção durante o inverno. A presença de compostos fenólicos na mucilagem, principalmente taninos, tem importância antimicrobiana e ainda, na proteção contra herbívoros, constituindo uma importante barreira de proteção química (Swain 1979; Carmello et al. 1995).

Considerando que H. pernambucensis habita sítios com alta incidência de radiação solar e luminosidade, temperaturas elevadas e solos com baixa capacidade de retenção de 
água e alta salinidade (Dansereau 1948; Walsh 1974; Araújo \& Maciel 1979), a presença de diferentes estruturas secretoras de mucilagem nos eixos vegetativos e reprodutivos, pode representar um importante mecanismo de sobrevivência das plantas, nas diferentes fases do ciclo de vida, aos ambientes de restinga e mangue. Na superfície da planta, a mucilagem atua protegendo estruturas em desenvolvimento contra a dessecação e ainda, na proteção contra herbivoria e patógenos. No interior da planta, pode atuar na reserva de água e carboidratos, no balanço hídrico, na resistência contra a seca e devido à presença de compostos fenólicos na secreção, pode atuar na proteção contra patógenos.

\section{Agradecimentos}

À CAPES/PICDT-UFRRJ pela bolsa de Doutorado concedida ao primeiro autor; ao CNPq pela bolsa de Produtividade em Pesquisa concedida à Silvia Rodrigues Machado; à FAPESP-Programa Biota, Processo 00/12469-3 pelo auxílio financeiro e ao Centro de Microscopia Eletrônica, Instituto de Biociência, UNESP, Câmpus de Botucatu, pela assistência técnica.

\section{Referências bibliográficas}

Alverson, W.S.; Karol, K.G.; Baum, D.A.; Chase, M.W.; Swensen, S.M.; McCourt, R. \& Systma, K.J. 1998. Circumscription of the Malvales and relationships to other Rosidae: Evidence from rbcL sequence data. American Journal of Botany 85: 876-887.

Amaral, L.I.V.; Pereira, M.F. \& Cortelazzo, A.L. 2001. Formação das substâncias de reserva durante o desenvolvimento de sementes de urucum (Bixa orellana L. - Bixaceae). Acta Botanica Brasilica 15: 125-132.

Appezzato-da-Glória, B. \& Estellita, M.E.M. 2000. Development, structure and distribution of colleters in Mandevilla illustris and M. Velutina (Apocynaceae). Revista Brasileira de Botânica 23: 113-120.

Araújo, D.S.D. \& Maciel, N.C. 1979. Os manguezais do recôncavo da baía de Guanabara. Rio de Janeiro, FEEMA.

Ascensão, L., Mota, L. \& Castro, M.D.M. 1999. Glandular trichomes on the leaves and flowers of Plectranthus ornatus: morphology, distribution and histochemistry. Annals of Botany 84: 437-447.

Ascensão, L.; Marques, N. \& Pais, M.S. 1995. Glandular trichomes on vegetative and reproductive organs of Leonotis leonurus (Lamiaceae). Annals of Botany 75: 619-626.

Bakker, M.E \& Baas, P. 1993. Cell walls in oil and mucilage cells. Acta Botanica Neerlandica 42: 133-139.

Bakker, M.E \& Gerritsen, A.F. 1992. The development of mucilage cells in Hibiscus schizopetalus. Acta Botanica Neerlandica 41: 31-42.

Barreiro, D.P. \& Machado, S.R. 2007. Coléteres dendróides em Alibertia sessilis (Vell.) K. Schum., uma espécie não-nodulada de Rubiaceae. Revista Brasileira de Botânica 30(3): 387-399.

Bouchet, P. \& Deysson, G. 1974. Les canaux à mucilage des Angiospermes: etude morphologique et ultrastructurale des cellules constituant les canaux à mucilage du Sterculia bidwilli Hook. Revue Generale de Botanique 81: 369-402.

Bukatasch, F. 1972. Bemerkungem zur doppel far burng AstrablauSafranin. Mikrokosmos 6: 255.

Carmelo, S.M., Machado, S.R. \& Gregório, E.A. 1995. Ultrastructural aspects of the secretory duct development in Lithraea molleoides (Vell.) Engl. (Anacardiaceae). Revista Brasileira de Botânica 18: 95-103.

Clifford, S.C., Arndt, S.K., Popp, M. \& Jones, H.G. 2002. Mucilages and polysaccharides in Ziziphus species (Rhamnaceae): localization, composition and physiological roles during drought-streess. Journal of Experimental Botany 53: 131-138.

Corsi, G. \& Bottega, S. 1999. Glandular hairs of Salvia officinalis: new data on morphology localization and histochemistry in relation to fuction. Annals of Botany 84: 657-664.

Da Cunha M, Vieira R.C. 1997. Anatomia foliar de Psychotria velloziana Benth. (Rubiaceae). Rodriguésia 49: 39-50.

Dansereau, P. 1948. Distribuição de zonas e sucessão na restinga do Rio de Janeiro. Boletim Geográfico 60: 1431-1443.

David, R. \& Carde, J.P. 1964. Coloration defférentielle des inclusions lipidique et terpeniques des pseudophylles du pine maritime au moyen du reactif Nadi. Comptés Rendus de l'Academie des Sciences Paris 258: $1338-1340$.

Esau, K. 1974. Anatomia das plantas com sementes. Tradução Berta Lange de Morretes. São Paulo, Edgard Blucher, Ed. Universidade de São Paulo.

Fahn, A. 1979. Secretory tissues in plants. London, Academic Press.

Fahn, A. 1990. Plant anatomy. $4^{\text {th }}$ ed. Oxford, Butterworth-Heinemann Ltd.

Fahn, A. 2000. Structure and function of secretory cells. Advances in Botanical Research 31: 37-75.

Fisher, D.B. 1968. Protein staining of ribboned epon sections for light microscopy. Histochemie 16: 92-96.

Gerlach, D. 1969. Botanische Mikrotechnik. Stuttgart, Georg Thieme Verlag.

Gerrits, P.O. 1991. The application of glycol methacrylate in histotechnology: some fundamental principles. Gröningen, Department of Anatomy and Embriology, State University of Gröningen.

Gregory, M. \& Baas, P. 1989. A survey of mucilage cells in vegetative organs of the dicotyledons. Israel Journal of Botany 38: 125-174.

Howart, W.O \& Horner, L.G.G. 1959. Practical Botany for the Tropics. London, University London Press.

Inamdar, J.A. \& Chohan, A.J. 1969a. Epidermal structure and stomatal development in some Malvaceae and Bombacaceae. Annals of Botany 33: 865-878.

Inamdar, J.A. \& Chohan, A.J. 1969b. Epidermal structure and ontogeny of stomata in vegetative and floral organs of Hibiscus rosa-sinensis $\mathrm{L}$. Australian Journal of Botany 17: 89-95.

Jensen, W.A. 1962. Botanical histochemistry: principles and pratice. San Francisco, W.H. Freeman 2 \& Co.

Johansen, D.A. 1940. Plant microtechinique. New York, MacGraw-Hill. Judd, W.S.; Campbell, C.S.; Kellogg, E.A.; Stevens, P.F. \& Donoghue, M.J. 2009. Sistemática Vegetal: um enfoque filogenético. 3 ed. Porto Alegre, Artmed.

Klein, D.E., Gomes, V.M., Silva-Neto, S.J. \& Da Cunha, M. 2004. The structure of colleters in several species of Simira (Rubiaceae). Annals of Botany 94: 733-740.

Kronestedt-Robards, E. \& Robards, A.W. 1991. Exocytosis in gland cells. Pp.199-232 In: Hawes, C.R.; Coleman, J.O.D. \& Evans, D.E. (Eds.). Endocytosis, exocytosis and vesicle traffic in plants. Cambridge, Cambridge University Press.

Lorenzi, H. 1992. Árvores brasileiras: manual de identificação e cultivo de plantas arbóreas nativas do Brasil. 2 ed. Nova Odessa, Plantarum.

Martini, M.H., Lenci, C.G. \& Tavares, D.Q. 2003. Mucilage pockets in cotiledon tissue of Theobroma speciosum. Acta Microscopica 12: 65-69.

Metcalfe, C.R. \& Chalk, L. 1950. Anatomy of dicotyledons. v. 1. Oxford, Clarendon Press.

Meyberg, M. 1988. Cytochemistry and ultrastructure of the mucilage secreting trichomes of Nymphoides peltata (Menyanthaceae). Annals of Botany 62: 537-547.

Mollenhauer, H.H. 1967. The fine structure of mucilage secreting cells of Hibiscus esculentus pods. Protoplasma 63: 353-362.

O’Brien, T.P., Feder, N. \& McCully, M.E. 1964. Polychromatic staining of plant cell walls by toluidine blue. Protoplasma 59: 368-373 .

Pio Corrêa, M. 1984. Dicionário das plantas úteis do Brasil e das exóticas cultivadas. v. 3. Rio de Janeiro, Ministério da Agricultura, IBDF.

Paiva, E.A.S. \& Machado, S.R. 2006a. Ontogenesis, structure and ultrastructure of Hymenaea stigonocarpa (Fabaceae: Caesalpinioideae) colleters. Revista de Biologia Tropical 54(3): 943-950. 
Paiva, E.A.S. \& Machado, S.R. 2006b. Colleters in Caryocar brasiliense (Caryocaraceae) ontogenesis, ultrastructure and secretion. Brazilian Journal of Biology 66(1B): 301-308.

Paiva, E.A.S. \& Martins L.C. 2011. Calycinal trichomes in Ipomoea cairica (Convolvulaceae): ontogenesis, structure and functional aspects. Australian Journal of Botany 59(1): 91-98.

Pimentel, R.R.; Machado, S.R. \& Rocha, J.F. 2011. Estruturas secretoras de Pavonia alnifolia (Malvaceae), uma espécie ameaçada de extinção. Rodriguésia 62(2): 253-262.

Priolo De Lufrano, N.S. \& Caffini, N.O. 1981. Mucílagos foliares de Chorisia H.B.K. (Bombacaceae): análisis fitoquímico e enfoque quimiotaxonômico. Phyton 40: 13-20.

Purvis, M.J., Collier, D.C. \& Walls, D. 1964. Laboratory techniques in botany. London, Butterwoths.

Ragonese, A.M. 1960. Ontogenia de los distintos tipos de tricomas de Hibiscus rosa-sinensis L. (Malvaceae). Darwiniana 12: 59-66.

Rickson, F.R. \& Risch, S.J. 1984. Anatomical and ultrastructural aspects of the ant-food cell of Piper cenocladum C.D.C. (Piperaceae). American Journal of Botany 71: 1268-1274.

Rio, M.C.S., Castro, M.M. \& Kinoshita, L.S. 2002. Distribuição e caracterização anatômica dos coléteres foliares de Prestonia coalita (Vell.) Wodson (Apocynaceae). Revista Brasileira de Botânica 25: 339-349.

Robbrecht, E. 1988. Tropical woody Rubiaceae. Caracteristics features and progressions. Contributions to a new subfamilial classification. Opera Botanica Belgica 1: 1-271.

Rocha, J.F. \& Neves, L.J. 2000. Anatomia foliar de Hibiscus tiliaceus L. e Hibiscus pernambucensis Arruda (Malvaceae). Rodriguésia 51: 113-132.

Rocha, J.F., Neves, L.J. \& Pace, L.B. 2002. Estruturas secretoras em folhas de Hibiscus tiliaceus L. e Hibiscus pernambucensis Arruda. Revista Universidade Rural, Série Ciências de Vida 22: 43-55.

Roshchina, V.V. \& Roshchina, V.D. 1993. The excretory fuction of higher plants. Berlin, Springer-Verlag.

Rougier, M. \& Chaboud, A. 1985. Mucilages secreted by roots and their biological function. Israel Journal of Botany 34: 129-146.

Sass, J.E. 1951. Botanical microtechnique. Iwoa, The Iwoa State College Press.

Sawidis, T.H. 1991. A histochemical study of nectaries of Hibiscus rosasinensis. Journal of Experimental Botany 24: 1477-1487.
Sawidis, T.H. 1998. The subglandular tissue of Hibiscus rosa-sinensis nectaries. Flora 193: 327-335.

Schnepf, E. 1969. Sekretion und exkretion bei pflanzen. Protoplasmatol Hanb Protoplasmaforsch 8: 1-181.

Scott, F.M. \& Bystrom, B.G. 1970. Mucilaginous idioblasts in Okra, Hibiscus esculentus L. Pp.15-24. In: Robson, N.K.B.; Cutler, D.F. \& Gregory, M. (Eds.). New research in plant anatomy. London, Academic Press.

Shimony, C.; Fahn, A. \& Reinhold, L. 1973. Ultrastructure and ion gradients in the salt glands of Avicennia marina (Forsk.) Vierh. New Phytologist 72: 27-36.

Silva, E.M.J. \& Machado, S.R. 1999a. Ultrastructure and cytochemistry of the pearl gland in Piper regnellii (Piperaceae). Nordic Journal of Botany 19: 623-634.

Silva, E.M.J. \& Machado, S.R. 1999b. Estrutura e desenvolvimento dos tricomas secretores em folhas de Piper regnellii (Miq.) C. DC. var. regnellii (Piperaceae). Revista Brasileira de Botânica 22: 117-124.

Solereder, H. 1908. Systematic anatomy of the dicotyledons. v.1. Oxford, Clarendon Press.

Stevens, P. F. (2001 em diante). Angiosperm Phylogeny Website. versão 9 de Junho de 2008. Disponível em http://www.mobot.org/MOBOT/ research/APweb/ (Acesso em 24/05/2011

Strasburger, E. 1924. Handbook of practical botany. $8^{\text {th }}$ ed. London, George Allen e Nonviirn, Ltd.

Swain, T. 1979. Tannins and lignins. Pp.657-682. In: Rosenthal, G.A. \& Jansen, D.H. (Eds.). Herbivores: their interactions with secondary plant metabolites. New York, Academic Press.

Thomas, V. 1991. Structural, functional and phylogenetic aspects of the colleter. Annals of Botany 68: 287-305.

Uphof, J.C.T. 1962. Plant hairs. 292p. In: Zimmermann, W. \& Ozenda, P.G. (Eds.). Handbuch der pflanzenanatomie. Berlin, Gebrüder Borntraeger.

Walsh, G.E. 1974. Ecology of halophytes. New York, Academic Press.

Webber, I.E. 1938. Anatomy of leaf and stem of Gossypium. Journal of Agricultural Research 57: 269-286.

Werker, E. \& Fahn, A. 1981. Secretory hairs of Inula viscosa (L.) Ait: development, utrastructure and secretion. Botanical Gazette 142: 461-466.

Youngman, W \& Pande, S.S. 1929. The epidermal outgrowts of the genera Thespesia e Gossypium. A morphology study throuwing some light upon the evolution of the hais constituting commercial cotton. Annals of Botany 43: 711-740. 